\title{
PHYSICAL ACTIVITY OF 15-17 YEARS OLD ADOLESCENTS IN DIFFERENT EDUCATIONAL SETTINGS: A POLISH-CZECH STUDY
}

\author{
Karel Frömel', Dorota Groffik², František Chmelík ${ }^{1}$, Armando Cocca ${ }^{3}, K_{\text {Krzysztof Skalik }}^{2}$ \\ ${ }^{1}$ Faculty of Physical Culture, Palacký University Olomouc, Olomouc, Czech Republic \\ ${ }^{2}$ Academy of Physical Education, University of Katowice, Katowice, Poland \\ ${ }^{3}$ College of Education and Human Development, Texas A\&M University, San Antonio, Texas, United States of America
}

\begin{abstract}
SUMMARY
Objectives: The aim of this study was to analyze adolescents' physical activity (PA) in two different educational settings, and to estimate the association between meeting PA recommendations and specific characteristics of adolescents' lifestyle.

Methods: The study was carried out in the Moravia region of the Czech Republic and in the Silesia-Opole region of Poland. In total, 1,846 participants completed the long International Physical Activity Questionnaire (IPAQ-long) using the online Indares system.

Results: Results showed that the Polish sample was significantly more physically active than the Czech one concerning school $\mathrm{PA}(\mathrm{p}<0.001$; $\left.\eta^{2}=0.07\right)$. Comparing by gender, significant differences were found in vigorous PA $\left(p<0.001 ; \eta^{2}=0.05\right)$ and moderate PA $\left(p<0.001 ; \eta^{2}=0.08\right)$ in both samples. The recommendations for vigorous PA are met by $45.9 \%$ of Czech boys and $33.4 \%$ of girls; and by $64.5 \%$ of Polish boys and $51.3 \%$ of girls. Participation in organized PA was the main correlate to achieve the recommendations of vigorous PA in both Czech ( $p<0.001$; $\mathrm{Cl}=4.47-9.25)$ and Polish adolescents $(\mathrm{p}<0.001 ; \mathrm{Cl}=1.99-5.37)$.

Conclusions: The Polish educational model seems to be more effective for enhancing higher levels of PA among youth, as it provides pupils with a wider offer of organized PA. Girls were found to be less active than boys at high PA intensities in both countries, therefore, more effort must be put on involving them in organized PA.
\end{abstract}

Key words: physical education, sports, secondary school, Internet, health

Address for correspondence: A. Cocca, College of Education and Human Development, Texas A\&M University, 1 University Way, 78224 San Antonio TX, United States of America. E-mail: armando.cocca@tamusa.edu

https://doi.org/10.21101/cejph.a4521

\section{INTRODUCTION}

Physical Activity (PA) represents one of the main variables influencing people's lifestyle (1). Authors agree in considering PA a key factor for enhancing individual and public health especially during childhood and adolescence, as most of the behaviours acquired in early ages are more likely to be maintained through adulthood (2).

Despite increased awareness of the importance of keeping an active lifestyle, recent research has highlighted a consistent decrease of PA among youth, as well as a drop in PA levels from childhood to adulthood and old age (3). Specifically, many authors have pointed out adolescence as the period of life in which the decline in PA habits becomes more apparent $(4,5)$.

As in many other regions of the world, Czech and Polish youth face similar conditions, the raise of sedentary behaviours having developed into a national concern in both countries $(6,7)$. Previous studies have underlined that boys in the Czech Republic and Poland are more physically active than girls at higher intensity of PA, whereas girls tend to engage in more leisure-time exercise (8). However, in both sexes weekly PA time seems not to be sufficient to trigger the well-known health benefits of exercising (9).
In latest years, schools have emerged as one of the ideal settings for promoting the culture of active lifestyle among youngsters, as well as for addressing and supporting gender-specific needs and interests with regard to PA (10). As a matter of fact, governmental laws of most of the countries around the world establish compulsory school attendance until the age of 16 (in some cases, even 18). For this reason, any intervention focused on PA habits in youth becomes easier in these contexts, as they allow to bypass the interference of disturbing variables such as family economy, parental support or accessibility of sports facilities, as well as other factors that cannot be controlled and commonly affect research on out-of-school PA (11).

In school environments, physical education (PE), organized school PA and recesses are considered the primary contributors to overall PA (12). Developing knowledge on the way these contributors are managed in schools is necessary if we aim to fully understand adolescents' lifestyle and promote effective, tailor-made changes in their PA behaviours (13). Additionally, comparing how different educational environments and systems handle school PA, emphasizing strong and weak points of each one, may be extremely useful to both research and practice as they aim to improve youth's PA habits in school settings. In fact, 
governments could be able to enhance their national educational structure by culturally adapting favourable features from different educational systems, consequently avoiding drawbacks of their socioeconomic, health, and education policies.

Nevertheless, only a few studies in the field of school PA have focused on educational systems' comparison to the date $(14,15)$. These studies are focused on contrasting students' motor skills, on highlighting cultural differences in the way school PA is delivered, or on evaluating different impacts of the same school programmes applied in educational centres from different countries. In the above-mentioned research, school environment is only mentioned as a factor that may influence those variables, while none of those studies examines in depth how each educational system could affect their participation in PA.

Therefore, the aims of this study were to analyze the levels of adolescents' school and out-of-school PA in two different educational settings, one in the Czech Republic and the other in Poland; and to estimate the association between meeting PA recommendations and specific adolescents' behaviours, i.e. engagement in PA, participation in organized PA, and sports modalities practiced in the last year.

\section{MATERIALS AND METHODS}

\section{Participants}

The research was carried out in randomly selected secondary schools from the Moravia region of the Czech Republic (30 schools, 1,117 participants) and from the Silesia-Opole region in Poland ( 22 schools, 729 participants). $85 \%$ of directors of the contacted schools gave their approval for participating in the study, while $15 \%$ of them denied access to their centres due to the impossibility to embed the project into their regular academic schedule. After the measurement sessions, 57 participants were excluded because they did not meet the requirements for data processing. The descriptive analysis of the sample is shown in Table 1.

\section{Design}

This research used a non-experimental design, since there was no variable manipulation and the sample was composed by natural groups (school classes), which were not modified for the study purposes.

\section{Instruments}

In order to estimate weekly PA, the long version of the International Physical Activity Questionnaire (IPAQ-long) was applied (16). The Czech version of the questionnaire was prepared in compliance with the translation guidelines of the European Organization for Research and Treatment of Cancer (EORTC) Quality of Life Group (17), and it was used in previous research in the same field (18). The Polish version had been previously validated and is available on the IPAQ official website*. Moreover, it has been used in prior studies on PA habits in youth (19). The IPAQ-long includes items on a wide range of PA types (job/ school-related; transportation; housework, house maintenance, and caring for family; recreation, sport, and leisure-time), as well as it provides information about the time spent sitting. In this instrument, the intensity of PA is divided into three main categories: vigorous - more than 6 Metabolic Equivalents of Tasks (METs); moderate - from 3 to 6 METs; and walking - less than 3 METs (20).

\section{Procedures}

The first step consisted of contacting the principals of the educational centres and asking for permission for developing the study. After obtaining their formal consent, the researchers made contact with the teachers, the students and their families, in order to explain the details of the study and ask for their agreement. Official agreement sheets, assuring that any personal information would be kept anonymous, were signed by both researchers and families. Successively, a measurement agenda was established based on the academic schedule of each school individually.

The IPAQ questionnaires were completed using the online Indares system ${ }^{* *}$ under personal supervision of the research team. The questionnaires were completed in computer labs in each of the schools involved in the study. Researchers' presence during the measurement sessions was necessary, since the structure of the IPAQ questionnaire, as well as its contents are complex and might require further explanation. Data from the questionnaires was processed in compliance with the correspondent IPAQ manual at the Centre for Kinanthropology Research in the Czech Republic.

The values of the Healthy People 2010 (21), 2008 Physical Activity Guidelines for Americans (22), and European Union Physical Activity Guidelines (23) were used as reference for the recommendations on PA in youth. Based on the above-mentioned PA intensity levels described in the IPAQ-long, these recommendations are as follows:

Table 1. Descriptive analysis of the sample $(N=1,846)$

\begin{tabular}{|c|c|c|c|c|c|c|c|c|c|c|}
\hline \multirow{2}{*}{ Country } & \multirow{2}{*}{ Gender } & \multirow{2}{*}{$n$} & \multicolumn{2}{|c|}{ Age } & \multicolumn{2}{|c|}{ Weight } & \multicolumn{2}{|c|}{ Height } & \multicolumn{2}{|c|}{ BMI } \\
\hline & & & Mean & SD & Mean & SD & Mean & SD & Mean & SD \\
\hline \multirow{2}{*}{ Czech Republic } & Boys & 449 & 15.80 & 1.06 & 68.62 & 10.51 & 178.62 & 7.52 & 21.46 & 2.69 \\
\hline & Girls & 668 & 15.93 & 1.08 & 58.14 & 8.43 & 167.23 & 6.37 & 20.76 & 2.59 \\
\hline \multirow{2}{*}{ Poland } & Boys & 296 & 15.83 & 0.84 & 66.54 & 11.05 & 176.41 & 7.38 & 21.32 & 2.85 \\
\hline & Girls & 433 & 15.92 & 0.81 & 56.33 & 8.54 & 165.50 & 6.15 & 20.54 & 2.75 \\
\hline
\end{tabular}

\footnotetext{
*http://www.ipaq.ki.se

$* *$ http://www.indares.com
} 
- Vigorous PA, at least 20 minutes on 3 or more days per week (3 times 20 minutes);

- Moderate PA, at least 30 minutes on 5 or more days per week (5 times 30 minutes);

- Walking, at least 30 minutes on 5 or more days per week (5 times 30 minutes);

- Moderate-to-vigorous PA, at least 60 minutes every day (7 times 60 minutes).

\section{Statistical Analysis}

Basic statistical values, pivot tables, Kruskal Wallis ANOVA and logistic regression analysis were used. For the effect size, $\eta^{2}$ and $d$ coefficients were calculated to provide comprehensive information. The $d$ coefficient with a value of $0.2 \leq d<0.5$ was interpreted as a small effect size, a $d$ of $0.5 \leq d<0.8$ was interpreted as a medium effect size, and a $d \geq 0.8$ was interpreted as a large effect size (24). The coefficient $\eta^{2}$ with a value of $0.01 \leq \eta^{2}<0.06$ was considered to be a small effect size, an $\eta^{2}$ of $0.06 \leq \eta^{2}<0.14$ was considered to be a medium effect size, and an $\eta^{2} \geq 0.14$ was considered to be a large effect size (25). The data were processed using the software Statistica 9 system and SPSS 19 for Windows.

\section{RESULTS}

Comparison between Czech and Polish Adolescents

Significant differences between PA in Polish and Czech adolescents were found in school PA $\left(\mathrm{H}=127.82 ; \mathrm{p}<0.001 ; \eta^{2}=0.07\right)$, as shown in Figure 1. Polish boys $(U=6.89 ; \mathrm{p}<0.001 ; \mathrm{d}=0.5)$ and Polish girls $(U=7.04 ; \mathrm{p}<0.001 ; \mathrm{d}=0.4)$ showed significantly more school PA than Czech boys and girls. In active transportation, there were significant differences as Polish boys $(\mathrm{H}=29.83$; $\left.\mathrm{p}<0.001 ; \eta^{2}=0.016\right)$ were found to be more active than the Czech ones $(\mathrm{U}=4.81 ; \mathrm{p}<0.001 ; \mathrm{d}=0.4)$. Further, in recreation, sport, and leisure-time physical activity Polish boys $(H=17.87 ; p=0.001$; $\left.\eta^{2}=0.01\right)$ obtained significantly higher values of PA than their Czech peers $(U=2.85 ; p=0.027 ; d=0.2)$. No statistically significant differences were found regarding PA levels in housework, house maintenance, and caring for family. The overall results are explained in Figure 1.

\section{Comparison by Gender}

Regarding gender comparison, significant differences were found in vigorous $\mathrm{PA}\left(\mathrm{H}=100.33 ; \mathrm{p}<0.001 ; \eta^{2}=0.05\right)$ and moderate PA $\left(H=152.85 ; \mathrm{p}<0.001 ; \eta^{2}=0.08\right)$, boys showing higher scores at both levels of PA. No differences were found between Polish boys and girls in walking activities. As regards to Czech participants, girls showed significantly higher levels of walking activities than boys, even if the significance was low $(U=2.66$; $\mathrm{p}=0.047 ; \mathrm{d}=0.2$ ). Intensity and levels of PA in both samples are shown in Figure 2.

\section{Vigorous-Intensity Physical Activity and Its Cor- relates}

The recommendations for vigorous PA ( $3 \times 20 \mathrm{~min})$ are met by $45.9 \%$ of Czech boys and $33.4 \%$ of Czech girls (OR $=0.75$; $\mathrm{p}=0.038 ; \mathrm{CI}=0.57-0.99)$; and by $64.5 \%$ of Polish boys and $51.3 \%$ of Polish girls $(\mathrm{OR}=0.69 ; \mathrm{p}=0.023 ; \mathrm{CI}=0.35-0.80)$. Participation in organized PA ( $\geq 3$ times a week) was a significant correlate of meeting recommendations for vigorous PA both in Czech $(\mathrm{OR}=6.43 ; \mathrm{p}<0.001 ; \mathrm{CI}=4.47-9.25)$ and Polish $(\mathrm{OR}=3.27$; $\mathrm{p}<0.001 ; \mathrm{CI}=1.99-5.37)$ adolescents. Another significant association was found for specific sports modalities that Czech $(\mathrm{OR}=1.60 ; \mathrm{p}=0.013 ; \mathrm{CI}=1.11-2.32)$ and Polish adolescents $(\mathrm{OR}=1.73 ; \mathrm{p}=0.004 ; \mathrm{CI}=1.19-2.52)$ declared to practice during the year. In Czech adolescents, higher chances of meeting the recommendations for vigorous PA are associated with increased use of passive transportation.

\section{Moderate-Intensity Physical Activity and Its Cor- relates}

Meeting the recommendations for moderate $\mathrm{PA}(5 \times 30 \mathrm{~min})$ is strongly correlated with participation in organized PA in Polish youth $(\mathrm{OR}=1.66 ; \mathrm{p}=0.041 ; \mathrm{CI}=1.02-2.71)$. On the other hand, these recommendations are associated with less time spent sitting $(\mathrm{OR}=0.69 ; \mathrm{p}=0.011 ; \mathrm{CI}=0.51-0.92)$ and with higher levels of

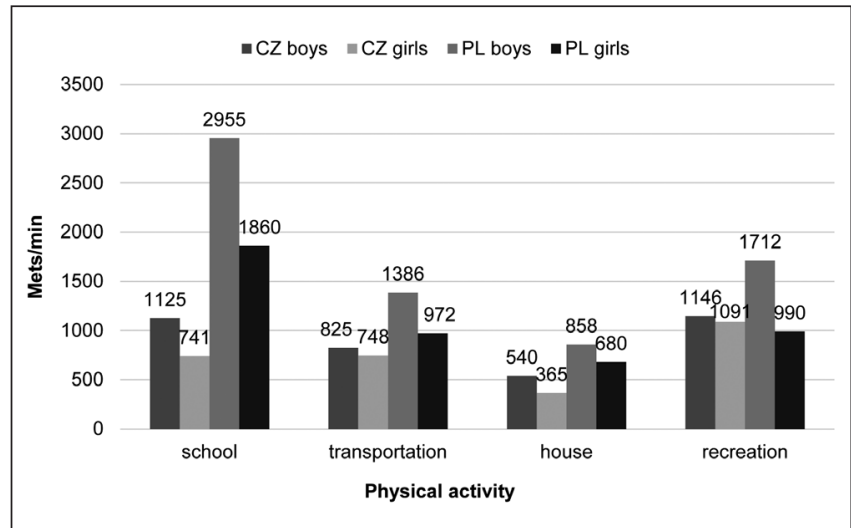

Fig. 1. Physical activity levels in Czech (CZ, $n=1,117)$ and Polish (PL, $n=729$ ) adolescents (Metabolic Equivalents of Tasks [METs]-min·day-1).

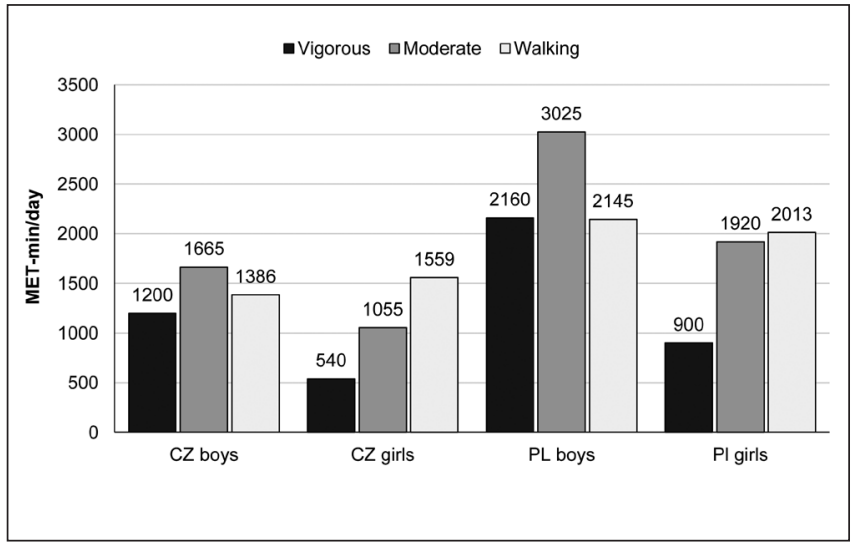

Fig. 2. Levels of physical activity in Czech $(C Z, n=1,117)$ and Polish (PL, $n=729$ ) adolescents (Metabolic Equivalents of Tasks [METs]-min·day ${ }^{-1}$ ) at different intensities. 
Table 2. Associations between selected correlates and meeting the recommendations for vigorous and moderate physical activity $(N=1,846)$

\begin{tabular}{|c|c|c|c|c|c|c|c|c|}
\hline \multirow{4}{*}{ Characteristic } & \multicolumn{8}{|c|}{ Meeting guidelines } \\
\hline & \multicolumn{4}{|c|}{$3 \times 20$ minutes - vigorous PA } & \multicolumn{4}{|c|}{$5 \times 30$ minutes - moderate PA } \\
\hline & \multicolumn{2}{|r|}{ Czechs } & \multicolumn{2}{|r|}{ Poles } & \multicolumn{2}{|c|}{ Czechs } & \multicolumn{2}{|r|}{ Poles } \\
\hline & $n(\%)$ & $\mathrm{OR}(\mathrm{Cl})$ & $n(\%)$ & $\mathrm{OR}(\mathrm{Cl})$ & $n(\%)$ & $\mathrm{OR}(\mathrm{Cl})$ & $\mathrm{n}(\%)$ & $\mathrm{OR}(\mathrm{Cl})$ \\
\hline \multicolumn{9}{|l|}{ Sex } \\
\hline Boys & $206(45.9)$ & ref & $191(64.5)$ & ref & $111(24.7)$ & ref & $157(53.0)$ & ref \\
\hline Girls & $223(33.4)$ & $0.75^{\star}(0.57-0.99)$ & $222(51.3)$ & $0.69 *(0.35-0.80)$ & $135(20.2)$ & $0.81(0.60-1.08)$ & $170(39.3)$ & $0.62^{* \star}(0.46-0.85)$ \\
\hline \multicolumn{9}{|l|}{ Age (years) } \\
\hline 15 & $178(39.7)$ & ref & $168(62.2)$ & ref & $106(23.7)$ & ref & $136(50.4)$ & ref \\
\hline 16 & $173(40.0)$ & $0.96(0.72-1.29)$ & $166(57.8)$ & $1.08(0.74-1.56)$ & $92(21.3)$ & $0.84(0.61-1.16)$ & $124(43.2)$ & $0.78(0.54-1.10)$ \\
\hline 17 & $78(33.1)$ & $0.97(0.68-1.40)$ & $79(45.9)$ & $0.70(0.45-1.07)$ & $48(20.3)$ & $0.89(0.60-1.31)$ & $67(39.0)$ & $0.67(0.44-1.02)$ \\
\hline \multicolumn{9}{|l|}{$\mathrm{BMI}\left(\mathrm{kg} / \mathrm{m}^{2}\right)$} \\
\hline $\begin{array}{l}<85 \text { th } \\
\text { percentile }\end{array}$ & $387(39.1)$ & ref & $368(56.5)$ & ref & $222(22.4)$ & ref & $289(44.4)$ & ref \\
\hline $\begin{array}{l}\geq 85 \text { th } \\
\text { percentile }\end{array}$ & $42(33.1)$ & $0.93(0.61-1.42)$ & $45(57.7)$ & $0.89(0.53-1.48)$ & $24(18.9)$ & $0.83(0.52-1.34)$ & $38(48.7)$ & $1.03(0.64-1.68)$ \\
\hline \multicolumn{9}{|c|}{ Engagement in PA } \\
\hline No & $51(25.5)$ & ref & $80(40.4)$ & ref & $46(23.0)$ & ref & $73(36.9)$ & ref \\
\hline Yes & $378(41.2)$ & $1.60^{*}(1.11-2.32)$ & $333(62.7)$ & $1.73^{* *}(1.19-2.52)$ & $200(21.8)$ & $0.86(0.59-1.25)$ & $254(47.8)$ & $1.28(0.88-1.86)$ \\
\hline \multicolumn{9}{|c|}{ Participation in organized PA } \\
\hline No & $75(22.5)$ & ref & $48(36.9)$ & ref & $71(21.3)$ & ref & $45(34.6)$ & ref \\
\hline $1-2 \times$ week & $148(31.0)$ & $1.51^{* *}(1.09-2.09)$ & $170(50.5)$ & $1.34(1.80-3.36)$ & $88(18.5)$ & $0.85(0.60-1.21)$ & $144(42.7)$ & $1.23(0.78-1.94)$ \\
\hline$\geq 3 \times$ week & $206(67.1)$ & $\begin{array}{c}6.43^{* * *} \\
(4.47-9.25)\end{array}$ & $195(74.4)$ & $\begin{array}{c}3.27^{* * *} \\
(1.99-5.37)\end{array}$ & $87(28.3)$ & $1.42(0.97-2.07)$ & $138(47.3)$ & $1.66^{*}(1.02-2.71)$ \\
\hline \multicolumn{9}{|l|}{ Sitting } \\
\hline$<360$ min & $188(44.7)$ & ref & $273(60.5)$ & ref & $110(26.1)$ & ref & $195(43.2)$ & ref \\
\hline$\geq 360 \min$ & $241(34.6)$ & $0.66^{* \star}(0.50-0.86)$ & $140(50.4)$ & $0.75(0.55-0.95)$ & $136(19.5)$ & $0.69^{*}(0.51-0.92)$ & $132(47.5)$ & $1.33(0.97-1.82)$ \\
\hline \multicolumn{9}{|c|}{ Passive transportation } \\
\hline$<30 \min$ & $212(35.8)$ & ref & $259(56.6)$ & ref & $114(19.3)$ & ref & $198(43.3)$ & ref \\
\hline$\geq 30 \mathrm{~min}$ & $217(41.3)$ & $1.45^{* *}(1.11-1.89)$ & $154(56.8)$ & $1.16(0.83-1.63)$ & $132(25.1)$ & $1.45^{*}(1.09-1.94)$ & $129(47.6)$ & $1.28(0.93-1.76)$ \\
\hline
\end{tabular}

OR - odds ratio, $\mathrm{Cl}$ - confidence interval, ${ }^{*} \mathrm{p}<0.05,{ }^{* *} \mathrm{p}<0.01,{ }^{* * *} \mathrm{p}<0.001$

transportation $(\mathrm{OR}=1.45 ; \mathrm{p}=0.011 ; \mathrm{CI}=1.09-1.94)$ in $\mathrm{Czech}$ adolescents. Gender represents an influential factor for meeting the recommendations for moderate PA in Polish adolescents $(\mathrm{OR}=0.62 ; \mathrm{p}=0.003 ; \mathrm{CI}=0.46-0.85)$, whereas it is not significant for Czech youth in this study. Results regarding PA recommendations are summarized in Table 2.

\section{Low-Intensity Physical Activity and Its Correlates}

Both Czech and Polish adolescents have the highest chances to meet the recommendations for walking ( 5 times 30 minutes) by participating in organized PA, as shown in Table 3. Recommendations for walking are met by $58.1 \%$ of Czech boys, gender representing a significant factor influencing its achievement $(\mathrm{OR}=1.36 ; \mathrm{p}=0.019 ; \mathrm{CI}=1.05-1.76)$. Other significant correlates of meeting the recommendation for walking in Czech adolescents are Body Mass Index (BMI) $(\mathrm{OR}=0.67 ; \mathrm{p}=0.040 ; \mathrm{CI}=0.46-0.98)$ and passive transportation $(\mathrm{OR}=1.91 ; \mathrm{p}<0.001 ; \mathrm{CI}=1.49-2.46)$.
Results showed that more time spent using passive transportation is positively correlated with higher walking activity. In Polish adolescents, the chances to meet the recommendations for walking increase from 16-year-old $(\mathrm{OR}=1.51 ; \mathrm{p}=0.028 ; \mathrm{CI}=1.08-2.66)$ to 17 -year-old participants $(\mathrm{OR}=2.06 ; \mathrm{p}=0.002 ; \mathrm{CI}=1.31-3.24)$.

\section{Moderate-to-Vigorous-Intensity Physical Activity and Its Correlates}

Participating in organized PA represents the main correlate to achieve the recommendations for moderate-to-vigorous PA (MVPA) (7 times 60 minutes) in both Czech and Polish adolescents. Further, meeting the MVPA recommendations is significantly influenced by the sports modalities practiced around the year by both Czech $(\mathrm{OR}=1.70 ; \mathrm{p}=0.021 ; \mathrm{CI}=1.08-2.66)$ and Polish $(\mathrm{OR}=1.87 ; \mathrm{p}=0.006 ; \mathrm{CI}=1.20-2.92)$ participants. In Czech participants, the achievement of MVPA recommendations is also linked to less than 360 minutes spent sitting $(\mathrm{OR}=1.87$; 
Table 3. Association between selected correlates and meeting the recommendation for walking physical activity (PA) and moderate to vigorous $P A(N=1,846)$

\begin{tabular}{|c|c|c|c|c|c|c|c|c|}
\hline \multirow{4}{*}{ Characteristic } & \multicolumn{8}{|c|}{ Meeting guidelines } \\
\hline & \multicolumn{4}{|c|}{$5 \times 30$ minutes - walking } & \multicolumn{4}{|c|}{$7 \times 60$ minutes - moderate to vigorous $\mathrm{PA}$} \\
\hline & \multicolumn{2}{|c|}{ Czechs } & \multicolumn{2}{|r|}{ Poles } & \multicolumn{2}{|c|}{ Czechs } & \multicolumn{2}{|r|}{ Poles } \\
\hline & $\mathrm{n}(\%)$ & $\mathrm{OR}(\mathrm{Cl})$ & $\mathrm{n}(\%)$ & $\mathrm{OR}(\mathrm{Cl})$ & $\mathrm{n}(\%)$ & $\mathrm{OR}(\mathrm{Cl})$ & $\mathrm{n}(\%)$ & $\mathrm{OR}(\mathrm{Cl})$ \\
\hline \multicolumn{9}{|l|}{ Sex } \\
\hline Boys & $261(58.1)$ & ref & $197(66.6)$ & ref & $145(32.3)$ & ref & $120(40.5)$ & ref \\
\hline Girls & $433(64.8)$ & $1.36^{*}(1.05-1.76)$ & $294(67.9)$ & $1.07(0.77-1.49)$ & $147(20.1)$ & $0.81(0.60-1.10)$ & $109(25.2)$ & $0.55^{* *}(0.39-0.77)$ \\
\hline \multicolumn{9}{|l|}{ Age (years) } \\
\hline 15 & $262(58.5)$ & ref & $163(60.4)$ & ref & $126(28.1)$ & ref & $98(36.3)$ & ref \\
\hline 16 & $279(64.4)$ & $1.25(0.95-1.65)$ & $199(69.3)$ & $1.51^{*}(1.05-2.18)$ & $115(26.6)$ & $0.87(0.62-1.21)$ & $97(33.8)$ & $1.14(0.78-1.66)$ \\
\hline 17 & $153(64.8)$ & $1.29(0.92-1.81)$ & $129(75.0)$ & $2.06^{* *}(1.31-3.24)$ & $51(21.6)$ & $1.00(0.66-1.51)$ & $34(19.8)$ & $0.54^{*}(0.33-0.88)$ \\
\hline \multicolumn{9}{|l|}{$\mathrm{BMI}\left(\mathrm{kg} / \mathrm{m}^{2}\right)$} \\
\hline $\begin{array}{l}<85 \text { th } \\
\text { percentile }\end{array}$ & $629(63.5)$ & ref & $439(67.4)$ & ref & $263(26.6)$ & ref & $203(31.2)$ & ref \\
\hline $\begin{array}{l}\geq 85 \text { th } \\
\text { percentile }\end{array}$ & 65 (51.2) & $0.67^{*}(0.46-0.98)$ & $52(66.7)$ & $1.00(0.60-1.67)$ & $29(22.8)$ & $1.09(0.67-1.77)$ & $26(33.3)$ & $0.87(0.51-1.48)$ \\
\hline \multicolumn{9}{|c|}{ Engagement in $\mathrm{PA}$} \\
\hline No & $128(64.0)$ & ref & $124(62.6)$ & ref & $30(15.0)$ & ref & $36(18.2)$ & ref \\
\hline Yes & $566(61.7)$ & $0.91(0.65-1.26)$ & $367(69.1)$ & $1.34(0.91-1.98)$ & $262(28.6)$ & $1.70^{*}(1.08-2.66)$ & $193(36.4)$ & $1.87^{* *}(1.20-2.92)$ \\
\hline \multicolumn{9}{|c|}{ Participation in organized PA } \\
\hline No & $201(60.4)$ & ref & 77 (59.2) & ref & $41(12.3)$ & ref & $22(16.2)$ & ref \\
\hline $1-2 \times$ week & $286(60.0)$ & $1.03(0.77-1.39)$ & $237(70.3)$ & $1.58(1.00-2.50)$ & $80(16.8)$ & $1.39(0.92-2.10)$ & $89(26.4)$ & $1.31(0.75-2.28)$ \\
\hline$\geq 3 \times$ week & $207(67.4)$ & $1.50^{*}(1.07-2.11)$ & $177(67.6)$ & $1.52^{*}(0.93-2.50)$ & $171(55.7)$ & $\begin{array}{c}8.37^{\star * \star} \\
(5.54-12.63)\end{array}$ & $118(45.0)$ & $2.45^{* * *}(1.39-4.32)$ \\
\hline \multicolumn{9}{|l|}{ Sitting } \\
\hline$<360 \min$ & $271(64.4)$ & ref & $299(66.3)$ & ref & $129(30.6)$ & ref & $156(34.6)$ & ref \\
\hline$\geq 360 \mathrm{~min}$ & $423(60.8)$ & $0.81(0.63-1.05)$ & $192(69.1)$ & $1.19(0.80-1.56)$ & $163(23.4)$ & $0.70 *(0.52-0.95)$ & $73(26.3)$ & $0.75(0.53-1.07)$ \\
\hline \multicolumn{9}{|c|}{ Passive transportation } \\
\hline$<30 \mathrm{~min}$ & $326(55.1)$ & ref & $294(64.2)$ & ref & $147(24.8)$ & ref & $145(31.7)$ & ref \\
\hline$\geq 30 \mathrm{~min}$ & $368(70.1)$ & $1.91^{* * *}(1.49-2.46)$ & $197(72.7)$ & $1.29(0.92-1.82)$ & $145(27.6)$ & $1.31(0.97-1.77)$ & $84(31.0)$ & $1.11(0.78-1.58)$ \\
\hline
\end{tabular}

OR - odds ratio, $\mathrm{Cl}$ - confidence interval, ${ }^{*} \mathrm{p}<0.05,{ }^{* *} \mathrm{p}<0.01,{ }^{* * *} \mathrm{p}<0.001$

$\mathrm{p}=0.006 ; \mathrm{CI}=1.20-2.92)$. On the other hand, gender $(\mathrm{OR}=0.55$; $\mathrm{p}=0.001 ; \mathrm{CI}=0.39-0.77)$ and higher age $(\mathrm{OR}=0.87 ; \mathrm{p}=0.013$; $\mathrm{CI}=0.51-1.48)$ have been found to be significant correlate in their Polish fellows (Table 3).

\section{Activities Carried Out Around the Year}

Czech and Polish girls engage most frequently in dance activities throughout the year (19.7\% of Czech, 13.2\% of Polish girls) and in volleyball (11.2\% of Czech, $11.1 \%$ of Polish girls). Further, they perform cycling $(9.8 \%$ of Czech, $5.5 \%$ of Polish girls) and swimming ( $6.2 \%$ of Czech, $6.5 \%$ of Polish girls). Boys engage most frequently in football $(28.4 \%$ of Czech, $24.3 \%$ of Polish boys) and in cycling activities ( $8.2 \%$ of Czech, $6.1 \%$ of Polish boys). Other frequent activities in Czech boys are floorball, hockey, and skating (10.7\% of Czech, but only $2.7 \%$ of Polish boys). Swimming activities are performed by $4 \%$ of Polish boys, whereas only $2 \%$ of Czech boys are engaged in them.

\section{DISCUSSION}

\section{Physical Activity Levels}

In our research, Polish adolescents obtained higher levels of school PA than their Czech peers. This result can be justified in different ways. Firstly, the Polish educational system includes a higher number of physical education (PE) lessons, as established in its curricula (26). According to the regulations of the Polish educational system, four 45-minute classes of PE per week must be carried out regardless of the educational level. On the other hand, the Czech educational system currently plans two 45-minute classes of PE weekly (27). This difference can create a large gap in the quantity of PA carried out by adolescents between the Polish and Czech communities. In our study, PA carried out at school accounts for $35.6 \%$ of total PA in Polish boys, but only for $32.4 \%$ in the Czech ones. Also, it represents $38.1 \%$ of total PA in Polish girls, while it constitutes only $29.6 \%$ in the Czech ones. Another reason of our 
outcomes can be that Polish adolescents have more opportunities to engage in after-school PA. After-school PA can be developed within the school setting and represents a critical window for promoting PA among youth, as well as for enhancing higher PA levels and reducing obesity risk (28). A study developed in the Czech Republic and focused on adolescents' PA demonstrated that exercising in after-school organized PA increases overall quantity of daily PA (29). Thus, it is clear that a wider offer of after-school activities could provide more favourable conditions for reaching higher PA levels. A question that must be taken into account is the influence of teachers, which is considered an important agent linked to PA levels. In fact, methodology employed as well as teaching techniques and styles can influence youth's engagement in PA (30). Nevertheless, in our research this variable has not been studied, thus it is difficult to estimate the impact of teachers' characteristics and education on the outcomes of this study.

\section{Physical Activity Intensity}

The high volume of vigorous and moderate PA in Polish boys and girls was a positive finding of our research. The emphasis that the Polish educational system puts on physical education could be a main cause of these outcomes (26). Different approaches to PE in the two countries may also explain the fact that Polish adolescents showed higher engagement in MVPA than their Czech fellows. For instance, PE focuses mostly on sports and training in Poland, this connoting higher importance given to fitness and performance than to other aspects of the physical domain. In the Czech Republic, as a result of the process of liberalization of pedagogic methods and of the education reform that took place in the last decade, sports and PE do not always blend together. In fact, Czech PE curricula have a high focus on health and motor learning, while sports modalities are more often performed as after-school activities. In addition, the government allows PE teachers to partially modify and adapt the national curricula based on the specific needs of their students.

Another aspect to take into account is boys' higher engagement in vigorous PA and in organized sports, which corresponds with the results found by Rychtecký et al. (31). Other studies developed worldwide corroborate our findings, putting into evidence boys' higher implication in high-intensity and/or organized PA compared to girls (32). High-intensity exercise is traditionally considered a masculine activity, which leads to a different psychological approach towards sports in both genders (33). In addition, research demonstrates that teachers may involuntarily adopt sexist behaviours that often determine a drop in girls' enjoyment of PE classes (34). Also, individual psychological variables such as boys' positive attitude towards physical effort or high perceived competence are considered strongly associated with their implication in vigorous exercise (35). Nonetheless, those variables were not included in our research and deeper analysis of them is required in the future. In contradiction with previous literature, no differences were found between Czech boys and girls in low intensity PA $(32,36)$. The fact that age did not constitute a determinant of Czech adolescents' total weekly PA represents an interesting result, since a similar study developed by Frömel et al. (37) in the same context showed a decline of PA over the years. On the other hand, differences by age were found in the Polish sample, both in boys (aged 15: 10,191 METs; aged 16: 8,443 METs; and aged 17: 8,133 METs) and girls (aged 15:
7,722 METs; aged 16: 6,729 METs; and aged 17: 6,140 METs). However, it must be noted that these findings cannot be read as tendencies due to the trans-sectional outline of this study.

\section{Meeting Physical Activity Recommendations}

The chances to meet PA recommendations are strengthened by participating in organized PA. In fact, in our study $64.1 \%$ of boys and $52.7 \%$ of girls engaging in those activities reached the recommended levels of PA. On the contrary, PA recommendations were met only by $39.8 \%$ boys and $28.3 \%$ girls who were not participating in any organized PA. These results are in line with previous literature. A study by Frömel et al. (37) showed that Czech boys $(\mathrm{OR}=2.60 ; \mathrm{p}<0.001 ; \mathrm{CI}=1.90-3.57)$ and girls $(\mathrm{OR}=2.59 ; \mathrm{p}<0.001 ; \mathrm{CI}=1.90-3.50)$ who engaged in any type of organized PA were more likely to meet PA recommendations. Cheung (38) adds that participation in after-school sports activities is positively related to high levels of PA and to meeting PA recommendations. In girls, who commonly show lower levels of PA, practicing sports often leads to higher chances of achieving health-related levels and weekly amount of PA (39).

\section{Most Frequently Performed Physical Activity per Year}

Our outcomes emphasize that both Czech (44.1\% of boys, $16 \%$ of girls) and Polish (40.5\% of boys, $19.9 \%$ of girls) adolescents favour team sports. Football is the most practiced sport in boys, whereas girls prefer volleyball. However, the most significant differences were found for dance activities, which are largely performed by girls, but not by boys. These results confirm a stereotyped attitude of adolescents towards sports, as previously underlined in other studies (33). This attitude may be the consequence of social influences such as from mass media or from parents' beliefs (40). Finally, the activities shared by both boys and girls are cycling, running, swimming, and toning exercises. These activities seem to be disconnected from sexist postures or gender preconceptions.

\section{CONCLUSION}

Our outcomes stress the need for improving the offer of school PE and after-school PA within the Czech educational environment, as the higher levels of PA in Polish adolescents demonstrate. Though the values from the Polish sample were generally high, still there is a wide portion of Polish adolescents who do not reach the minimum quantity of PA necessary for enhancing health. Consequently, increasing the amount of PA offer and PE time cannot be used as the only instrument for promoting youth's engagement in PA. Factors such as social context, psychological aspects, and quality of teaching, as well as teachers' knowledge and education must be taken into account in the future in order to plan adequate PA interventions within school settings.

\section{Acknowledgement}

This paper was supported by the project "Support for the creation of excellent research teams and intersectoral mobility at Palacký University, Olomouc" (CZ.1.07/2.3.00/30.0004), and Multifactorial research of built environment, active lifestyle, and physical fitness of Czech 
youth (GA14-26896S). We thank Dr. Michaela Cocca for reviewing the language of the manuscript.

\section{Conflict of Interests}

None declared

\section{Adherence to Ethical Standards}

The study received the approval of the Ethic Committee of the Faculty of Physical Culture of Palacký University Olomouc (Czech Republic).

\section{REFERENCES}

1. Cox AE, Ullrich-French S. The Motivational relevance of peer and teacher relationship profiles in physical education. Psychol Sport Exerc. 2010 Sep;11(5):337-44.

2. Heaven PCL. Adolescent health: the role of individual differences. London (UK): Routledge; 1996.

3. Verloigne M, Van Lippevelde W, Maes L, Yildirim M, Chinapaw M, Manios Y, et al. Levels of physical activity and sedentary time among 10- to 12-year-old boys and girls across 5 European countries using accelerometers: an observational study within the ENERGY-Project. Int J Behav Nutr Phys Act. 2012 Mar 31;9:34. doi: 10.1186/1479-5868-9-34.

4. Peltzer K. Leisure time physical activity and sedentary behavior and substance use among in-school adolescents in eight African countries. Int J Behav Med. 2010 Dec;17(4):271-8.

5. Williams ED, Stamatakis E, Chandola T, Hamer M. Assessment of physical activity levels in South Asians in the UK: findings from the Health Survey for England. J Epidemiol Community Health. 2011 Jun;65(6):51721

6. Sigmundová D, El Ansari W, Sigmund E, Frömel K. Secular trends: a ten-year comparison of the amount and type of physical activity and inactivity of random samples of adolescents in the Czech Republic. BMC Public Health. 2011 Sep 26;11:731. doi: 10.1186/1471-2458-11-731.

7. Wojtyla A, Bilinski P, Bojar I, Wojtyla K. Physical activity among junior high school adolescents in Poland. Probl Hig Epidemiol. 2011;92(2):33542. (In Polish.)

8. Hubáčková R, Groffik D, Skrzypnik L, Frömel K. Physical activity and inactivity in primary and secondary school boys' and girls' daily program. Acta Gymnica. 2016;46(4):193-200.

9. Iannotti RJ, Chen R, Kololo H, Petronyte G, Haug E, Roberts C. Motivations for adolescent participation in leisure-time physical activity: international differences. J Phys Act Health. 2013 Jan;10(1):106-14.

10. Bonell C, Parry W, Wells H, Jamal F, Fletcher A, Harden A, et al. The Effects of the school environment on student health: a systematic review of multi-level studies. Health Place. 2013 May;21:180-91.

11. Hesketh KR, Lakshamn R, van Sluijs EMF. Barriers and facilitator to young children's physical activity and sedentary behaviour: a systematic review and synthesis of qualitative literature. Obes Rev. 2017 Sep;18(9):987-1017.

12. Pate RR, Davis MG, Robinson TN, Stone EJ, McKenzie TL, Young JC Promoting physical activity in children and youth: a leadership role for schools: a scientific statement from the American Heart Association Council on Nutrition, Physical Activity, and Metabolism (Physical Activity Committee) in Collaboration with the Councils on Cardiovascular Disease in the Young and Cardiovascular Nursing. Circulation. 2006 Sep 12;114(11):1214-24.

13. Siega-Riz AM, El Ghormli L, Mobley C, Gillis B, Stadler D, Hartstein J, et al. The Effects of the HEALTHY study interventionon middle schoo students dietary intakes. Int J Behav Nutr Phys Act. 2011 Feb 4;8:7. doi: 10.1186/1479-5868-8-7.

14. Bauman A, Ma GS, Cuevas F, Omar Z, Waqanivalu T, Phongsavan P, et al. Cross-national comparisons of socioeconomic differences in the prevalence of leisure-time and occupational physical activity, and active commuting in six Asia-Pacific countries. J Epidemiol Community Health 2011;65(1):35-43

15. Lee O, Choi E. A Comparison of Korean and U.S. physical education teacher education systems. KEDI J Educ Policy. 2011;8(2):235-58.

16. Craig CL, Marshall AL, Sjöström M, Bauman AE, Booth ML, Ainsworth $\mathrm{BE}$, et al. International physical activity questionnaire: 12-country reliability and validity. Med Sci Sports Exerc. 2003 Aug;35(8):1381-95.
17. Dewolf L, Koller M, Velikova G, Johnson CD, Scott N, Bottomley A EORTC Quality of Life Group translation procedure. Brussels: EORTC; 2009.

18. Pelclová J, Vašíčková J, Frömel K, Djordjevic I. Leisure time, occupational, domestic, and commuting physical activity of inhabitants of the Czech Republic aged 55-69: influence of socio-demographic and environmental factors. Acta Univ Palacki Olomuc Gymn. 2009;39(3):13-20.

19. Bergier J, Kapka-Skrzypczak L, Bilinski P Paprzycki P, Wojtyla A. Physical activity of Polish adolescents and young adults according to IPAQ: a population based study. Ann Agric Environ Med. 2012;19(1):109-15.

20. Ridley K, Ainsworth BE, Olds TS. Development of a compendium of energy expenditures for youth. Int J Behav Nutr Phys Act. 2008 Sep 10;5:45. doi: 10.1186/1479-5868-5-45.

21. U. S. Department of Health and Human Services. Healthy people 2010: understanding and improving health. Washington, DC: HHS; 2000.

22. 2008 physical activity guidelines for Americans: be active, healthy, and happy! Washington, DC: U. S. Department of Health and Human Services; 2008.

23. European Commission. EU physical activity guidelines: recommended policy actions in support of health-enhancing physical activity. Brussel: DG EAC; 2008.

24. Cortina JM, Nouri H. Effect size for ANOVA design. Thousand Oaks: Sage; 2000.

25. Morse DT. (1999). MINSIZE2: a computer program for determining effect size and minimum sample size for statistical significance for univariate, multivariate, and nonparametric tests. Educ Psychol Meas. 1999 Jun 1; 59(3):518-31.

26. Jung-Miklaszewska J. The system of education in the Republic of Poland. Warsaw: Bureau for Academic Recognition and International Exchange; 2003.

27. Eurydice. Organization of the education system in the Czech Republic. Brussels: European Commission; 2009.

28. Hastmann TJ, Bopp M, Fallon EA, Rosenkranz RR, Dzewaltowski DA. Factors influencing the implementation of organized physical activity and fruit and vegetable snacks in the HOP'N after-school obesity prevention program. J Nutr Educ Behav. 2013 Jan-Feb;45(1):60-8.

29. Pelclová J, El Ansari W, Vašíčková J. Is participation in after-schoo physical activity associated with increased total physical activity? A study on high school pupils in the Czech Republic. Int J Environ Res Public Health. 2010 Jul;7(7):2853-65

30. Keegan R, Spray C, Harwood C, Lavallee D. The Motivational atmosphere in youth sport: coach, parent, and peer influences on motivation in specializing sport participants. J Appl Sport Psychol. 2010 Feb;22(1):87-105.

31. Rychtecký A, editor. Monitoring youth participation in sports and physical exercise in the Czech Republic. Pague: Charles University; 2006. (In Czech.)

32. Laguna Nieto M, Lara Hernández MT, Aznar Laín S. Physical activity patterns by gender and obesity levels in Spanish school children. European Youth Heart Study (EYHS). Rev Psicol Deporte. 2011;20(2):621-36.

33. Clément-Guillotin C, Cambon L, Chalabaev A, Radel R, Michel S, Fontayne P. Social value and asymmetry of gender and sex categories in physical education. Rev Eur Psychol Appl. 2013;63(2):75-85.

34. Del Castillo Andrés O, Romero Granados S, Gonzáles Ramírez T, Campos Mesa MC. Gender equity in physical education: the use of information. Sex Roles. 2012;67(1-2):108-21.

35. Tsitskari E, Kouli O. Intrinsic motivation, perception of sport competence, and life-satisfaction of children in a Greek summer sport camp. World Leis J. 2010;52(4):279-89.

36. Ozdol Y, Ozer MK, Pinar S, Cetin E. Investigation of physical activity levels by gender and residential areas: a case study on students in Akdeniz University. Procedia Soc Behav Sci. 2012;46:1581-6.

37. Frömel K, Chmelík F, Bláha L, Feltlová D, Fojtík I, Horák S, et al. Czech youth physical activity: correlates of intense physical exercise. Ceska Kinantropol. 2007;11(4):49-55. (In Czech.)

38. Cheung PPY. Association of after-school physical activity levels and organized physical activity participation in Hong Kong children. Eur Phys Educ Rev. 2012;18(2):182-90.

39. Guagliano JM, Rosenkranz RR, Kolt GS. Girls' physical activity levels during organized sports in Australia. Med Sci Sports Exerc. 2013 Jan;45(1):116-22.

40. Catikkas F. Physical correlates of college students' body image satisfaction levels. Soc Behav Personal. 2011;39(4):497-502. 